\title{
Feasibility Analysis of Introduction of Folk Traditional Sports into Physical Education Curriculum Resources in Colleges and Universities in Xinjiang
}

\author{
Zhao Zhang \\ Department of Physical Education \& Research \\ Xinjiang University \\ Urumqi, Xinjiang, 830046
}

\begin{abstract}
This article uses the literature material method to analyze the main problems in physical education curriculum in colleges and universities in Xinjiang, and puts forward that it is feasible to introduce the folk traditional sports into the physical education curriculum resources in colleges and universities in Xinjiang. It can not only inherit the folk sports culture, realize sports characteristics of colleges and universities in Xinjiang, but also meet the requirements for teaching innovation in "Outline". It is conducive to the mining of sports teaching content for colleges and universities in Xinjiang. It is suggested to establish the traditional sports association in colleges and universities in Xinjiang, build folk traditional sports bases, develop traditional folk sports assessment and evaluation methods and strengthen the publicity of folk traditional sports culture in campus.
\end{abstract}

Keywords-folk traditional sports; colleges and universities in Xinjiang; physical education curriculum

\section{INTRODUCTION}

In August 2002, the Ministry of Education issued "Physical Education Curriculum Guiding Outline for Regular Institutes of Higher Education in China". The new "Outline" broke the fixed mode in original PE teaching outline. It has reformed the traditional content dominated by competitive sports, widened the content and structure of new physical education curriculum, especially for three types of course contents. The selection of compulsory, optional and elective courses enables the unfixed teaching to be management objective. This new objective setting can stimulate students' interests in sports learning, and help promote the physical and mental health of students. Thus, it can broaden the course content of physical education teachers, benefit the transformation of physical education teachers from passive execution to active participation in the teaching ideas of curriculum, and help physical education teachers become the initiator of the physical education. The folk traditional sports of Xinjiang have unique characteristics, rich cultural content, and a variety of types. It gives priority to leisure and entertainment, fitness sports, which is popular among the majority of students. Colleges and universities in

Fund Project: National Social Science Foundation of China (15BTY084), Social Science Planning Project of Xinjiang Uygur Autonomous Region (2015BTY097); Autonomous Region Arts Base Bidding Project of Xinjiang Normal University (XJEDU040612B03).
Xinjiang explore and introduce folk traditional sports in PE curriculum resources, which have the significance of the times and the value of its own advantages. The folk traditional sports have rich cultural connotations and unique national regional culture attraction, which is very important to the inheritance of the folk traditional sports culture. Folk traditional sports are very popular among the mass, various in type, rich in content, and easy to learn. The requirements for ground and equipment are also simple, which is also its advantage. Meanwhile, it can meet the internal demand of the physical education curriculum. The folk traditional sports are good for the physical and mental health of college students. Along with the rapid development of modern society, modern culture and modern sports greatly impact the traditional culture and traditional sports. The development of folk traditional sports culture is subjected to unprecedented challenges. Some folk traditional sports begin to fail to be handed down from past generations. Some folk etiquette and customs reflecting the traditional virtues are gradually fading. As an integral part of the traditional culture of minorities, the folk traditional sports are gradually moving towards the edge of the culture. It constantly shows a situation of cultural backwardness. By consulting the documents and interviews, we found that some of Xinjiang folk traditional sports have been lost, and some are falling to the edge of being lost. If we want to inherit and carry forward the folk traditional sports, it is necessary to find a scientific, healthy, systematic way of inheritance. In recent years, some folk traditional sports are protected and developed through physical education in school. Especially some colleges and universities have built a good development platform and space for some classic and outstanding folk traditional sports [1].

\section{The Problems EXISTING IN THE PHYSICAL}

EDUCATION CURRICULUM RESOURCES IN COLLEGES AND UNIVERSITIES IN XINJIANG

\section{A. The Lagging Curriculum Content Setting and Teaching} Content Tradition

The promulgation and implementation of the "Outline" first enable the content setting and reform of physical 
education curriculum to develop towards a diversified direction. But, from the teaching outline of physical education curriculum in colleges and universities in Xinjiang, design concept, the structural framework of curriculum content and the structure system of sports, teaching schedule and difficult points, it can be seen that the planning and development of physical education curriculum system are imbalanced in colleges and universities in Xinjiang.

\section{B. The Lack of Grounds, Facilities and Equipment in the Teaching of Physical Education}

Through the survey, it is found that currently colleges and universities in Xinjiang lack the supporting facility resources for physical education teaching. Compared with the number of students, the number of sports fields is relative short. The facilities and equipment are difficult to meet the needs. The average student occupancy rate of sports field is very low. At the same time, influenced by college sports field management level and students' exercise habits, the utilization rate of the relatively limited sports fields is very low.

\section{The Motorless Mining and Development of Curriculum Resources}

Most of physical education teachers in colleges and universities in Xinjiang have the concept of profession orientation. They are not willing and do want to make innovation. For a long time, the concept of physical education teachers in colleges and universities is still obsolete, and they lack communication in such information. The management departments of colleges and departments of physical education are afraid to make trouble, so they don't support or encourage the development and mining of new curriculum resources. They could just maintain the status quo of teaching. The course content arrangement follows the tradition. So, they neglect the development and utilization of new good sports, especially the development of own unique regional folk traditional sports. They know little of the new "Outline", and misunderstand it.

\section{THE FEASIBILITY OF INTRODUCING THE FOLK TRADITIONAL SPORTS INTO THE PHYSICAL EDUCATION CURRICULUM RESOURCES IN COLLEGES AND UNIVERSITIES IN XINJIANG}

\section{A. To Promote the Inheritance and Development of Traditional Folk Sports Culture}

Xinjiang has unique geographical environment and location. It is a place with many nationalities, various religions and multi-cultures, which create a unique folk traditional sports culture. It is also a reflection of cultural integration and emotion blending of each nationality in Xinjiang. Therefore, it has a far-reaching significance to inherit and develop traditional folk sports culture. However, with continuous update of modern society and continuous expansion of urban culture, some primitive folk traditional sports cultures in Xinjiang are gradually disappearing. The folk traditional sports of Xinjiang also face enormous surviving difficulties in its development. It is concretely showed in diminishing content and fractured inheritance. At present, it can not only pass down its own primitive sports but also a variety of folk traditional cultures in Xinjiang to introduce folk traditional sports in physical education curriculum resources in colleges and universities in Xinjiang. College students in Xinjiang can feel the charm of traditional folk sports culture. And it is an important way to protect and develop the folk traditional sports Colleges and universities spread and popularize the folk traditional sports and culture, which can influence students unconsciously, and enable students to understand the cultural connotations and characteristics of their own nationalities [2].

\section{B. To Realize the Physical Education Characteristics of Colleges and Universities in Xinjiang}

The physical education characteristics of colleges and universities refer to its unique school-running style in physical education compared with similar colleges and universities in a certain area. Colleges and universities shall start from its own reality in physical education, give full play to its own geographical environment and cultural advantages and traditions, and creatively implement the educational policy, so as to form its own unique and inherent personality and style. Xinjiang has the most abundant folk traditional sports culture resources, so colleges and universities in Xinjiang should fully and reasonably develop their advantages in order to achieve distinctive local ethnic characteristics. Folk traditional sports and modern sports have their roots in the category of cultural education. They can build body and entertain people's cultural life, which is the embodiment of its most fundamental value [3]. Therefore, in developing the human's physical quality and activity ability, the practice methods of traditional sports and modern sports can complement each other and learn from each other. The organic combination of modern sports and folk traditional sports will make physical education close to life, interesting, meaningful and valuable. So, colleges and universities can exploit and arrange folk traditional sports and introduce into physical education. It can directly associate with the public, and help students form good habits to participate in physical exercise. The reasonable introduction of folk traditional sports can not only enrich the physical education of colleges and universities, but also is conducive to enhancing the physical and mental health of college students in Xinjiang. It is the most effective way for colleges and universities in Xinjiang to develop sports undertakings. Seen from the fitness values and cultural characteristics, the introduction of folk traditional sports can not only meet the spirits of the "Outline", but also the need of characteristic physical education of colleges and universities in Xinjiang. Xinjiang is located in the western border, so sports fields and facilities of colleges and university and their numbers are far behind these of developed cities. But the folk traditional sports of Xinjiang have their own unique cultural characteristics. They can not only meet regional characteristics and climate characteristics of Xinjiang and, but also easy to carry out. If colleges and universities in Xinjiang introduce these folk traditional sports into physical education curriculum resources system, it can not only realize the physical education characteristics of colleges and universities in Xinjiang, but also accord with the local schoolrunning purposes and reflect the resources advantage of local schools. Therefore, it is a good idea to adjust measures according to local conditions and highlight the characteristics. And it is an effective way to realize the physical education 
characteristics of colleges and universities and make full use of Xinjiang's unique folk sports resources [4].

\section{To Meet the Requirements for Teaching Innovation in the "Outline"}

Many folk traditional sports of Xinjiang are suffering evolution, sedimentation and development, and they have adapted to the baptism and the impact of modern sports culture. They have transformed into classic folk traditional sports. Some sports can become elements of physical education in school. Even though folk traditional sports are various in expressive forms, they have same functions. They are good for physical and mental health, and can build body and entertain people's life, so the essence is similar to that of modern sports. Limited by economic, cultural and social development, colleges and universities in Xinjiang are relatively backward in teaching methods, teaching ideas, teaching content, teaching mode and even running conditions, compared with colleges and universities in other areas. Xinjiang is a multi-ethnic area. The proportion of minority students is considerably high in colleges and universities, which is a common phenomenon in Xinjiang. Minority students are very familiar with their own folk traditional sports, because they have participated in from an early age. They are very interested in these sports, so their learning interests are very strong. It's better to arrange special personnel and teachers to organize the study. It is understood that the current college students in Xinjiang have a relatively high acceptance of the traditional folk sports. The "Outline" requires colleges and universities in Xinjiang to carry out reform and innovation on physical education. The development of folk traditional sports in colleges and universities in Xinjiang meets the requirements of the "Outline" in participating in sports, promoting physical and mental health, and sports technology and adapting to society, and promoting the comprehensive improvement of the physical fitness of college students. The characteristics of folk traditional sports also determine the advantage value in the development [5].

\section{Conductive to Excavating the Physical Education}

Teaching Content in Colleges and Universities in Xinjiang

It is an effective way to perfect and enrich the physical education teaching content of colleges and universities in minority areas, help students increase national cultural knowledge and develop sports skills, and improve the emotion blend of nationalities to actively develop, mine and exploit folk traditional physical education resources. With fun, popularization quality and the function of fitness, folk traditional sports have become an important resource for the physical education in colleges and universities in Xinjiang. It is a supplement to physical education content of colleges and universities in Xinjiang. Most of the traditional folk sports resources can become materials for course development of colleges and universities in Xinjiang. It not only makes the physical education content of colleges and universities diversified and flexible, but also provides new development and utilization space for physical teaching innovations and reform in colleges and universities in Xinjiang [6].

\section{THE COUNTERMEASURES OF THE INTRODUCTION OF THE FOLK TRADITIONAL SPORTS INTO THE PHYSICAL EDUCATION CURRICULUM RESOURCES IN COLLEGES AND UNIVERSITIES IN XINJIANG}

\section{A. To Establish Folk Traditional Sports Associations in Colleges and Universities in Xinjiang}

The sports association of college students is an important part of college physical education. It is also one of the most important ways for students to enrich extracurricular life. It can attract students loving folk traditional sports to exercise to establish the folk traditional sports association. They can organize high-level sports competitions and performances and create campus's cultural atmosphere of folk traditional sports.

\section{B. To Establish the Folk Traditional Sports Base in Colleges and Universities in Xinjiang}

Colleges and universities in Xinjiang can build their own folk traditional sports bases according to their own conditions and sites and facilities. In this way, it can ensure to carry out the organization and protection of folk traditional sports designedly. They can also carry out systematic classification according the characteristics and exercise ways of sports, and then gradually test and promote these sports in school, thus make these sports standard, systematic and scientific.

\section{To Develop Folk Traditional Sports Assessment and Evaluation Methods}

It is an objective need for the introduction of the folk traditional sports into the curriculum resources to establish scientific assessment and evaluation methods. Most of folk traditional sports are for fitness and entertainment, so it is difficult to develop the evaluation methods. It is mainly reflected by the participation degree of college students and its effect. Therefore, the learning assessment and evaluation content of folk traditional sports is mainly according students' learning skills, attitude, physical quality, and cooperation spirit to carry out qualitative and quantitative analysis.

\section{To Strengthen the Publicity and Create A Folk Traditional Sports Culture Atmosphere in Campus}

Colleges and universities can vigorously promote folk traditional sports through campus radio, campus network and campus media, and give full play to the strength of campus media, so as to show the cultural value of folk traditional sports roundly. With continuous publicity of entertainment, fitness and other characteristics of folk traditional sports, college students may feel and be exposed to the rich content and unique charm of folk traditional sports culture unconsciously, and be well infected and nurtured. It can provide students with correct education and guidance, enrich their campus culture activities, and provide opportunities to know and participate in folk traditional sports. It can deepen students' knowledge and understanding on folk traditional sports. Students may positively share their happiness from these sports. Therefore, it is an important way to further promote the development of folk traditional sports to create a rich campus culture atmosphere of folk traditional sports in colleges and universities in Xinjiang. 


\section{REFERENCES}

[1] Li Chen. Feasibility and Path of the Introduction of Regional National Traditional Sports in Rural Primary and Secondary Schools in Ethnic Minority Areas - Taking Guizhou Province for Example. Journal of Beijing Sport University, May 2010: 33 (5).

[2] Li Na, Li Yingxia \& Meng Fengnian. Item Group Classification of Introduced Traditional Sports of Northwest Minorities in Physical Education in School. New West. 2011: (12).

[3] Liang Tianyu. Feasibility Study of Carrying out Minority Traditional Sports in School. Journal of Xianning University, 2010: 9 (9).

[4] Sun Yongmei, Wang Yongjun. The Necessity and Feasibility of Introduction of National Traditional Sports into School Education. Sports Journal, 2012: 19 (1).

[5] Gao Caiyan. The Status Quo of Traditional Ethnic Sports in Primary and Secondary Schools - Taking the Primary and Secondary Schools in Changchun Nanguan for Example. Modern Sports Science and Technology, 2013: 15 (3).

[6] Wang Wenqi, Zhang Shicai. Study on Current Situation and Countermeasures of Physical Education in Rural Schools in Less Developed Areas. Modern Sports Science and Technology, 2013: 22 (3). 